\title{
Erratum zu: Leistungsgerechtigkeit und Bildungsungleichheit
}

\section{Effekte der Verbindlichkeit der Grundschulempfehlungen beim Übergang auf das Gymnasium. Ein Vergleich der deutschen Bundesländer mit den Daten der ,National Educational Panel Study"(NEPS)}

\section{Hartmut Esser $\cdot$ Kerstin Hoenig}

Online publiziert: 5. November 2018

(C) Springer Fachmedien Wiesbaden GmbH, ein Teil von Springer Nature 2018

\section{Erratum zu:}

\section{Köln Z Soziol 2018}

https://doi.org/10.1007/s11577-018-0558-2

Leider wurde beim Druck versehentlich die falsche Abb. 1 verwendet. Außerdem muss es in Fußnote 8 statt „Fußnote 8“ „Fußnote 6“ heißen.

Die Online-Version des Originalartikels ist unter https://doi.org/10.1007/s11577-018-0558-2 zu finden.

\footnotetext{
H. Esser $(\bowtie)$

MZES, Universität Mannheim

68131 Mannheim, Deutschland

E-Mail: hartmut-esser@t-online.de

K. Hoenig

Leibniz-Institut für Bildungsverläufe (LIfBi)

Wilhelmsplatz 3, 96047 Bamberg, Deutschland

E-Mail: kerstin.hoenig@lifbi.de
} 


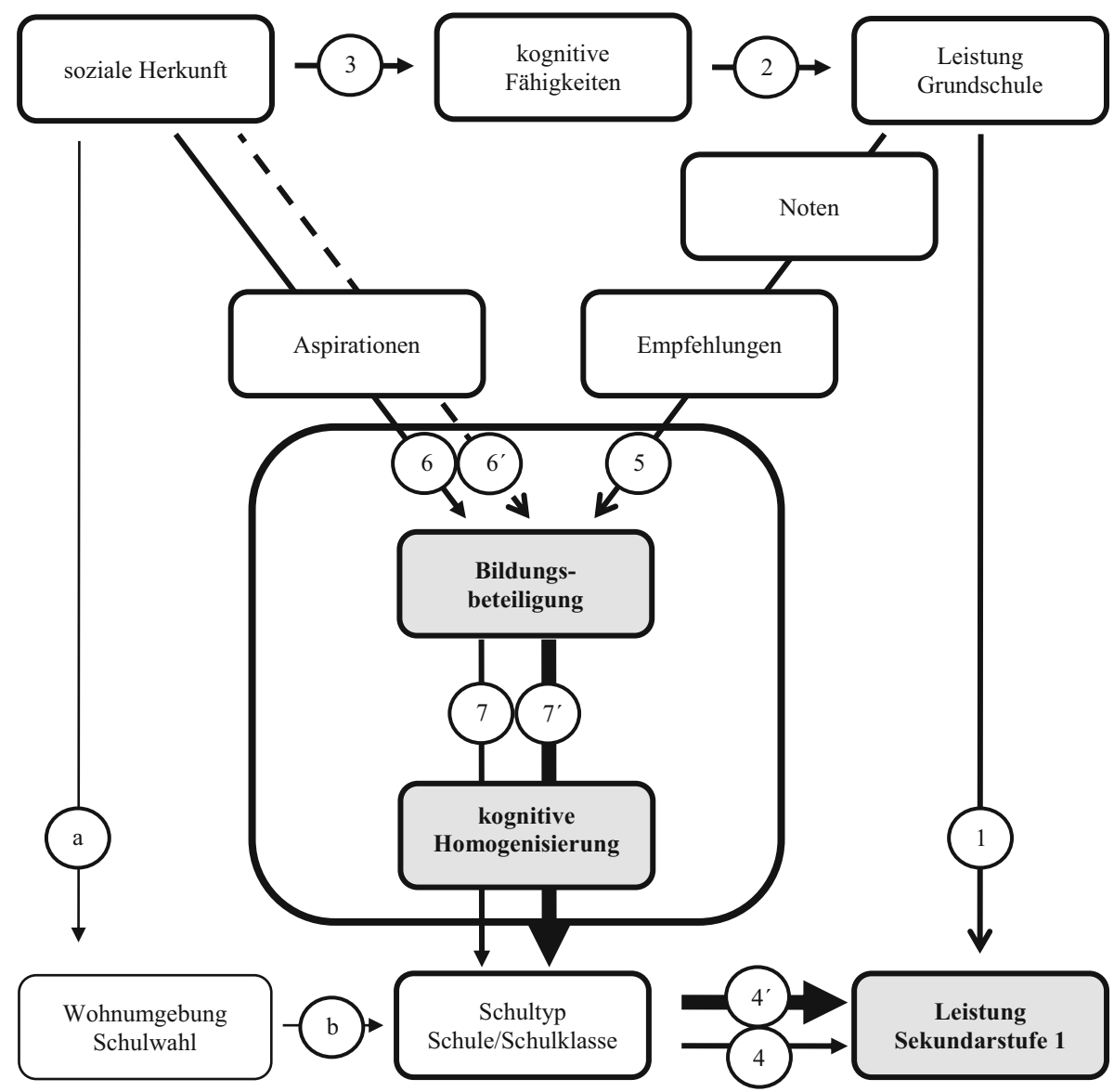

Abb. 1 Das Modell der Leistungsdifferenzierung (MoAbiT) und die Effekte der Verbindlichkeit 